\title{
A IMPORTÂNCIA DOS FATORES HUMANOS NO DESENVOLVIMENTO DE PRODUTOS COM ELEVADO DESEMPENHO AMBIENTAL: ESTUDO DE CASOS ${ }^{I}$
}

\section{THE SUPPORT OF HUMAN RESOURCE MANAGEMENT FACTORS FOR THE DEVELOPMENT OF ENVIRONMENTALLY-FRIENDLY PRODUCTS: CASE STUDIES}

\author{
CHARBEL JOSÉ CHIAPPETTA JABBOUR \\ Doutor em Engenharia de Produção pela Escola de Engenharia de São Carlos. \\ Professor da Faculdade de Economia, Administração e Contabilidade da Universidade de São Paulo (FEA-USP). \\ Avenida Bandeirantes, 3.900, Monte Alegre - Ribeirão Preto - São Paulo - SP - Brasil - CEP 14040-900 \\ E-mail: cjabbour@terra.com.br \\ FERNANDO CÉSAR ALMADA SANTOS \\ Doutor em Administração pela Escola de Administração de Empresas de \\ São Paulo da Fundação Getulio Vargas (FGV). \\ Professor Doutor do Departamento de Engenharia de Produção da Escola de Engenharia de São Carlos. \\ Avenida Trabalhador São Carlense, 400, Centro - São Carlos - São Paulo - Brasil - CEP 13566-590 \\ E-mail: almada@sc.usp.br

\section{ANA BEATRIZ LOPES DE SOUSA JABBOUR} \\ Mestre em Engenharia de Produção pela Escola Politécnica da Universidade de São Paulo (USP). \\ Professora do Departamento de Engenharia de Produção da Universidade Federal de São Carlos (UFSCar). \\ Rodovia João Leme dos Santos, Km 110 , SP-264, Bairro do Itinga \\ Sorocaba - São Paulo - Brasil - CEP 18052-780 \\ E-mail: beatriz@dep.ufscar.br
}

Os autores agradecem ao Centro de Estudos em Sustentabilidade da Escola de Administração de Empresas de São Paulo da Fundação Getulio Vargas (Eaesp/FGV) e à Fundação de Amparo à Pesquisa do Estado de São Paulo (Fapesp) o financiamento desta pesquisa. 


\section{RESUMO}

Este artigo analisa a incorporação de critérios ambientais no desenvolvimento de produtos, a partir da verificação das contribuições dos fatores de recursos humanos para esse processo. Para tanto, após a revisão teórica, conduziu-se um estudo de casos em duas empresas brasileiras. Há indícios de que, quanto maior o nível de excelência em desenvolvimento de produtos com elevado desempenho ambiental, maior é a interação desse processo com os fatores de recursos humanos. Por fim, são registradas as principais oportunidades para a continuidade dessa linha de pesquisa.

\section{PALAVRAS-CHAVE}

Gestão ambiental; Produtos com elevado desempenho ambiental; Recursos humanos; Sustentabilidade; Brasil.

\section{ABSTRACT}

The aim of this paper is to discuss the incorporation of environmental criteria into product development, highlighting the contributions of human resource management factors. The literature review is complemented by two case studies carried out in Brazilian companies. It is possible to conclude that the more environmentally-friendly products are developed with excellence, the more this type of product development interacts with human resource management factors. Finally, the main ways for continuing the analysis of this paper are presented.

\section{KEYWORDS}

Environmental management; Environmentally-friendly products; Human resource management; Sustainability; Brazil. 


\section{INTRODUÇ ÃO}

As principais propostas concernentes à melhoria da relação empresa-meio natural perpassam, necessariamente, por transformações no processo de desenvolvimento de produtos das organizações, rumando-se à concepção e ao desenvolvimento de produtos com elevado desempenho ambiental (HIRSCHL; KONRAD; SCHOLL, 2003; TINGSTRÖM; SWANSTRÖM; KARLSSON, 2006; WAAGE, 2007; NISSINEN et al., 2007; LUTTROPP; LAGERSTEDT, 2006; BYGGETH; BROMAN; ROBÈRT, 2007). Logicamente, as pesquisas que exploram a inserção de questões ambientais no desenvolvimento de produtos destacam a grande complexidade desse processo (ROTHENBERG, 2007), o qual demanda esforço organizacional considerável (PUJARI; WRIGHT; PEATTIE, 2003) e alterações de proporções paradigmáticas, isto é, um "repensar" do desenvolvimento de produtos à luz de princípios e técnicas ambientalmente alinhados (LUTTROPP; LAGERSTEDT, 2006).

Esse novo padrão requer, por seu turno, apoio da gestão de pessoas (DAILY; HUANG, 200I) tanto para selecionar pessoal apropriado a esse novo e complexo processo organizacional, com o propósito de configurar treinamentos e sistemas de avaliação de desempenho e de remuneração, quanto para articulação de equipes, gestão da aprendizagem organizacional e dos valores ambientais compartilhados pelos funcionários. A despeito da relevância da integração entre práticas de gestão de pessoas e desenvolvimento de produtos com elevado desempenho ambiental, raras são as pesquisas que se detêm ao estudo desse fenômeno, por meio da condução de reflexões teórico-empíricas.

Como consequência, torna-se plausível a investigação do desenvolvimento de produtos ambientalmente adequados, como prática organizacional, por meio de um enfoque sobre as práticas de gestão de pessoas que apoiam tal processo em empresas brasileiras. Com isso, objetiva-se fazer frente à seguinte questão de pesquisa: como e quais são as práticas de gestão de pessoas que apoiam a consideração de questões ambientais no processo de desenvolvimento de produtos? Assim sendo, são objetivos desta pesquisa: a) explorar o estado da arte dos temas relativos à gestão ambiental empresarial e sua relação com o processo de desenvolvimento de produtos, com destaque para as práticas de gestão de pessoas que o suportam; b) apresentar os resultados de uma pesquisa de campo realizada em duas organizações, à luz das suas práticas de gestão ambiental, desenvolvimento de produtos e práticas de recursos humanos adotadas. 


\section{INSERINDO A DIMENSÃO AMBIENTAL NO PROCESSO DE DESENVOLVIMENTO DE PRODUTO}

As iniciativas de gestão ambiental no contexto organizacional (Quadro I) requerem necessariamente o apoio da função produção (ANGELL; KLASSEN, I999) por meio do alinhamento das estratégias de desenvolvimento de processos (KUEHR, 2007), gestão da qualidade (ABOULNAGA, I998), logística (WU; DUNN, I995) e produto para a estratégia de gestão ambiental da empresa (MATHIEUX et al., 200I). Como consequência, importantes pesquisas vêm ressaltar a importância de as empresas possuírem uma função produção ambientalmente responsável, definida da seguinte forma:

[...] um sistema que integra as questões de desenvolvimento de produtos e processos no planejamento e controle da produção, de forma a identificar, quantificar, avaliar e gerenciar o fluxo produtivo, reduzindo ou eliminando os impactos ambientais gerados, ao mesmo tempo que maximiza a eficiência do sistema (HANDFIELD et al., 200I, p. I89).

\section{QUADRO I}

PRINCIPAIS DEFINIÇÕES DE GESTÃO AMBIENTAL EMPRESARIAL

\begin{tabular}{ll}
\hline PESQUISA & DEFINIÇÃO DE "GESTÃO AMBIENTAL EMPRESARIAL" \\
\hline Nahuz (1995, p. 62) & $\begin{array}{l}\text { "É o conjunto dos aspectos da função geral de gerenciamento } \\
\text { de uma organização, inclusive o planejamento, necessário para } \\
\text { desenvolver e manter a política e os objetivos ambientais da } \\
\text { organização." }\end{array}$ \\
\hline $\begin{array}{l}\text { Richards e Frosch } \\
\text { (1997) }\end{array}$ & $\begin{array}{l}\text { Um conjunto de atividades que objetiva a projeção de produtos, } \\
\text { processos produtivos e estratégias que evitem o surgimento de } \\
\text { problemas ambientais. }\end{array}$ \\
\hline McCloskey e & $\begin{array}{l}\text { O conjunto de ajustes e planejamentos da estrutura, dos sistemas e } \\
\text { das atividades da empresa a fim de estabelecer determinado tipo de } \\
\text { posicionamento ante a variável ambiental. }\end{array}$ \\
\hline "Processo adaptativo e dinâmico, por meio do qual as organizações \\
definem e redefinem suas expectativas e metas relacionadas à \\
proteção do ambiente, selecionando estratégias e meios para atingir \\
esses objetivos num tempo determinado, por meio de constante \\
avaliação de sua interação com o meio ambiente externo."
\end{tabular}


Como consequência, a incorporação das questões ambientais na manufatura só será uma realidade quando o desenvolvimento de produtos for orientado para cumprir objetivos de adequação ambiental (SHERWIN, 2004). Nesta pesquisa, assume-se que é o processo de desenvolvimento de produto que direciona a função produção ambientalmente responsável, uma vez que o produto ambientalmente projetado tende a induzir um processo de produção pautado na adoção de tecnologias mais limpas, a ser acompanhado de uma expansão no conceito de qualidade do produto que passa a incorporar aspectos de desempenho ambiental e a requerer uma gestão logística ambientalmente adequada (Quadro 2).

Pujari, Wright e Peattie (2003) discorrem acerca das principais influências sobre a efetividade do desenvolvimento de produtos ambientais. Esses desafios podem ser agrupados em três subconjuntos de fatores: (a) desafios de gestão, relacionados à existência e manutenção de um sistema de melhores práticas e à grande interfuncionalidade exigida; (b) desafios técnicos, concernentes à utilização e à disponibilidade de informações requeridas pela ferramenta Análise do Ciclo de Vida (ACV), que objetiva verificar e mitigar os impactos ambientais de um dado produto desde a extração de matérias-primas até seu descarte pós-consumo; e (c) obstáculos gerados pelas características históricas da gestão ambiental da empresa, que envolvem fatores como apoio da alta administração à causa ambiental, existência de uma política ambiental explícita, envolvimento de fornecedores no desenvolvimento de produtos ambientais e propriedades da coordenação da área de meio ambiente da empresa.

\section{QUADRO 2}

PRINCIPAIS DEFINIÇÕES DE DESENVOLVIMENTO DE PRODUTOS COM ELEVADO DESEMPENHO AMBIENTAL

\begin{tabular}{ll}
\hline PESQUISA & DEFINIÇÃO DE "DESENVOLVIMENTO DE PRODUTOS AMBIENTAIS" \\
\hline $\begin{array}{l}\text { Pujari, Wright e Peattie } \\
(2003)\end{array}$ & $\begin{array}{l}\text { Prática organizacional em que questões ambientais são integradas } \\
\text { no processo de desenvolvimento de produto. }\end{array}$ \\
\hline $\begin{array}{l}\text { Kaebernick, Kara e Sun } \\
(2003)\end{array}$ & $\begin{array}{l}\text { Desenvolvimento de produtos que abarca novas características } \\
\text { ambientais do produto, as quais evidenciam potencial de melhorar } \\
\text { sua qualidade geral ante as exigências dos consumidores. }\end{array}$ \\
\hline É um processo marcado pela projeção e produção de produtos \\
não agressivos ao meio ambiente, que sejam eficientes no \\
consumo de energia e de recursos naturais, e que possam ser \\
reciclados, reutilizados ou armazenados de forma segura.
\end{tabular}


Nesta pesquisa, o desenvolvimento de produtos ambientais é considerado como a incorporação de aspectos ambientais durante todas as fases do processo de desenvolvimento de produtos (JOHANSSON, 2006), apoiada por:

- Princípios e técnicas de Design for Environment (DfE) (TISCHINER; NICKEL, 2003) e Análise do Ciclo de Vida (ACV) (FINKBEINER et al., 2006), os quais apoiam as decisões de como os produtos podem ser ambientalmente melhorados (BOONS, 2002). Abordam-se as decisões sobre reciclagem, redução, reutilização ou substituição de componentes. Pertencem a esse conjunto ferramentas que quantificam o desempenho ambiental de um produto.

- Suporte fornecido por especialistas sobre eventuais alterações na legislação ambiental, regulamentações setoriais, demandas dos consumidores etc. Por exemplo, nesse grupo de iniciativas encontra-se a iniciativa Eiatrack (BOIRAL, 2006), um portal financiado pelas empresas líderes do setor de produtos eletrônicos para garantir informações ambientais dos principais países do mundo.

- Base de dados sobre custos ambientais que auxilia na avaliação dos efeitos das mudanças ambientais nos produtos sobre os custos de produção (HANDFIELD et al., 200I).

- Sistemas de informações e aprendizagem organizacional sobre impactos ambientais, com séries históricas sobre o desempenho ambiental de um dado produto e de seus subcomponentes (NISSINEN et al., 2007).

Essa consideração, completa e sistêmica, tende, entretanto, a ser viável apenas em organizações cuja gestão ambiental encontra-se em elevado nível de maturidade, após ter passado pelos estágios evolutivos (taxonomias) típicos de responsabilidade ambiental. As taxonomias da gestão ambiental empresarial são temas de diversas pesquisas (HUNT; AUSTER, I990; HART, I995; AZZONE; BERTELLÉ; NOCI, I997; MAIMON, I996; DONAIRE, I999; SANCHES, 2000; CORAZZA, 2003; BARBIERI, 2004; ROHRICH; CUNHA, 2004; SEIFFERT, 2005; POLIZELLI; PETRONI; KRUGLIANSKAS, 2005). Dada essa pluralidade de propostas, este trabalho utiliza a denominação de Jabbour e Santos (2006), que propõem uma denominação comum para grande parte desses trabalhos.

Segundo Jabbour e Santos (2006), as ações empresariais em gestão ambiental podem ser contempladas à luz de três estágios evolutivos (ou níveis de maturidade). Esses estágios se distinguem em termos de: a) articulação entre os objetivos ambientais e a estratégia empresarial, e b) com relação à efetividade das ações de gestão empresarial. Na década de I970, houve predominância da especialização funcional como paradigma de gestão ambiental; entre I980 e I990, muitas empresas desenvolveram suas atividades dentro do paradigma da inte- 
gração interna; e, atualmente, a integração externa desponta como paradigma da relação entre empresa e meio ambiente, principalmente nas empresas dos países mais desenvolvidos do globo.

$\mathrm{Na}$ especialização funcional (estágio reativo de gestão ambiental), ocorre a institucionalização das atividades ambientais na empresa, que coincide com a determinação de uma área funcional, isto é, a integração pontual da questão ambiental (CORAZZA, 2003) é necessária para que a organização possa reagir de forma adequada às pressões da legislação ambiental. A especialização funcional se justifica à medida que a organização incorpora equipamentos de controle de poluição nas saídas, sem modificar a estrutura produtiva e o produto (MAIMON, I996; BARBIERI, 2004). A especialização da função ambiental, por ser marcadamente reativa (DONAIRE, I994), não se preocupa com o ambiente competitivo nem com a formulação de uma ecoestratégia. O princípio básico desse primeiro estágio é evitar a geração de problemas ambientais para a cúpula administrativa, no que tange à consecução da estratégia empresarial corrente. Por vezes, a gestão ambiental é incumbência, apenas, de alguns advogados ou engenheiros (SEIFFERT, 2005).

No paradigma de integração interna da variável ambiental (estágio intermediário de maturidade), há a determinação das atividades ambientais com base nos objetivos de desempenho da empresa, principalmente no que concerne aos objetivos de prevenção da poluição. O desempenho ambiental da empresa não é, ainda, tratado como fator estratégico, e os objetivos de prevenção são estabelecidos sem a participação dinâmica da área ambiental (SEIFFERT, 2005). O desempenho da gestão ambiental é baseado no cumprimento das legislações ou exigências do mercado, segundo a interpretação da cúpula organizacional. Assim, cabe à gestão ambiental adequar o conteúdo de seus programas e de suas políticas à estratégia dos negócios vigentes.

No paradigma de integração externa (estágio de gestão ambiental estratégica), as atividades da gestão ambiental são integradas à estratégia empresarial, focadas na exploração de oportunidades estratégicas identificadas no ambiente competitivo da empresa (ROSEN, 200I). Segundo Donaire (I999), esse posicionamento organizacional se iniciou, historicamente, quando grandes empresas químicas da Alemanha ocidental começaram a verificar que as despesas realizadas com a gestão ambiental se transformavam em vantagem competitiva. Maimon (I996) classificou esse grupo de empresas - que compreende a gestão ambiental como fator condicionante de sua competitividade - de organizações possuidoras do "comportamento ético ambiental".

Ainda segundo Maimon (I996), esse modelo se contrapõe ao comportamento reativo, passando a tratar o meio ambiente como uma nova oportunidade de negócio tanto do ponto de vista tecnológico quanto organizacional. Boons (2002, 
p. 495) salienta que esse estágio tende a coincidir com um novo enfoque sobre o processo de desenvolvimento de produtos, o qual prima por uma perspectiva de desenvolvimento de produtos mais holística, que se dedique à melhoria ambiental dos fluxos de insumo aos fluxos pós-consumo, isto é, durante todo o ciclo de vida de um dado produto, desde sua concepção até seu descarte. Tal abordagem pode gerar benefícios para as empresas adotantes, conforme as categorias sistematizadas a seguir:

- Acesso a mercados de consumidores ambientalmente conscientes, por meio da exploração de estratégias de marketing ambiental (GINSBERG; BLOOM, 2004).

- Possibilidade de exportação da produção para países com legislação ambiental mais severa que a do país de origem (SEIFFERT, 2005).

- Valorização das ações da empresa, conforme propõe o Dow Jones Sustainability Group Index (PRESTON, 200I).

- Geração de vantagens financeiras por meio da exploração da imagem institucional ambientalmente correta da empresa (MILES; COVIN, 2000).

- Redução do montante despendido com multas ambientais (HUNT; AUSTER, I990).

- Geração de inovações em produtos e processos, oriundas do incremento da preocupação ambiental empresarial (PORTER; LINDE, I995).

A exploração desses benefícios pode ser levada a cabo por meio da consideração de melhores práticas de desenvolvimento de produtos ambientais:

- Utilização de materiais reciclados (FINKBEINER et al., 2006).

- Envolvimento dos fornecedores (POLONSKY; OTTMAN, I998; PUJARI, 2006).

- Substituição de matérias-primas (FINKBEINER et al., 2006).

- Design para a desmontagem (JOHANSSON, 2006).

- Avaliação do atendimento aos critérios ambientais durante o desenvolvimento (TINGSTRÖM; SWANSTRÖM; KARLSSON, 2006).

- Gerenciamento das informações ambientais (NISSINEN et al., 2007).

Entretanto, para alguns autores (TINGSTRÖM; SWANSTRÖM; KARLSSON, 2006), a despeito de ser possível a identificação de práticas e princípios organizacionais para o desenvolvimento de produtos ambientais, é fortemente evidenciado na literatura que a incorporação desses aspectos desponta mais como uma proposta teórica do que uma prática organizacional. Apesar de alguns exemplos eviden- 
ciarem transformações nesse sentido, eles geralmente revelam preocupação apenas com aspectos técnicos do desenvolvimento de produtos (FINKBEINER et al., 2006). Essa dissonância entre teoria e prática pode ser atribuída à pouca ênfase dada aos fatores humanos do desenvolvimento de produtos ambientalmente sustentáveis. Como afirmam importantes pesquisas (GOVINDARAJULU; DAILY, 2004; STONE, 2000), alterações técnicas para a inclusão da questão ambiental no contexto do desenvolvimento de produtos não garantem per se a transformação necessária. Assim, faz-se necessária a investigação dos fatores de recursos humanos que interferem no desempenho do processo de desenvolvimento de produtos ambientais.

\section{FATORES HUMANOS NO DESENVOLVIMENTO DE PRODUTOS COM ELEVADO DESEMPENHO AMBIENTAL}

É amplamente reconhecido pela literatura especializada que a incorporação de aspectos ambientais em processos organizacionais requer a gestão de fatores humanos (JABBOUR; SANTOS, 2008; GOVINDARAJULU; DAILY, 2004; DAILY; HUANG, 200I). Entretanto, paradoxalmente, estudos que abordam essa relação de forma mais profunda são extremamente escassos, como afirmam literalmente Brío, Fernández e Junquera (2007). Neste trabalho, os fatores de recursos humanos - as variáveis não técnicas que influenciam o desempenho da incorporação dos aspectos ambientais nas organizações e principalmente no processo de desenvolvimento de produtos - são classificados em tradicionais e competitivos.

Os fatores tradicionais de recursos humanos dizem respeito às práticas difundidas de gestão de pessoas, incluindo: análise e descrição de cargos, recrutamento e seleção, treinamento, avaliação de desempenho e recompensas. Já os fatores competitivos de recursos humanos referem-se às práticas dessa função que estão orientadas para a consecução da estratégia corporativa: articulação de equipes, gestão da cultura organizacional e práticas de aprendizagem organizacional. O Quadro 3 explora conceitualmente cada um dos fatores de recursos humanos propostos, enfatizando sua contribuição e seu escopo no contexto da gestão ambiental empresarial. 


\section{QUADRO 3}

\section{E IMPORTÂNCIA ORGANIZACIONAL

\begin{tabular}{|c|c|c|}
\hline $\begin{array}{l}\text { ATOR DE } \\
\text { RECURSOS } \\
\text { HUMANOS }\end{array}$ & DEFINIÇÃO TRADICIONAL & $\begin{array}{l}\text { DEFINIÇÃO NO CONCEITO } \\
\text { DA GESTÃO AMBIENTAL } \\
\text { EMPRESARIAL }\end{array}$ \\
\hline $\begin{array}{l}\text { Análise e } \\
\text { descrição de } \\
\text { cargos }\end{array}$ & $\begin{array}{l}\text { Análise e descrição de } \\
\text { um conjunto homogêneo } \\
\text { de atividades e tarefas } \\
\text { afins que compõem } \\
\text { determinado cargo } \\
\text { (MILKOVICH; BOUDREAU, } \\
\text { 2000). }\end{array}$ & $\begin{array}{l}\text { Inserção de aspectos } \\
\text { ambientais no } \\
\text { conjunto de descrições } \\
\text { de cargos da empresa, } \\
\text { isto é, a questão } \\
\text { ambiental torna-se } \\
\text { dever de todos na } \\
\text { empresa. }\end{array}$ \\
\hline
\end{tabular}

DEFINIÇÕES DOS FATORES DE RECURSOS HUMANOS: ABORDAGEM CLÁSSICA, NO CONTEXTO DA GESTÃO AMBIENTAL

Atividade organizacional que objetiva localizar e incentivar candidatos potenciais a disputar vagas existentes ou

Recrutamento previstas. Assim, o recrutamento pretende influenciar a quantidade e a tipologia dos candidatos à determinada vaga (IVANCEVICH, 1995).
IMPORTÂNCIA PARA

A GESTÃO AMBIENTAL EMPRESARIAL

A inserção das questões ambientais em todas as descrições de cargo torna o comprometimento com o meio ambiente um dever dos funcionários, ao lado de suas atividades típicas.

Torna explícito o interesse da empresa

As atividades de em contratar recrutamento, interno funcionários ou externo, explicitam a preferência comprometidos com a gestão ambiental, da empresa por candidatos podendo-se selecionar pessoal com comprometidos com o meio ambiente. experiência prévia na área, tanto para o recrutamento interno quanto para o externo.
Enquanto o processo de recrutamento objetiva aumentar a quantidade de candidatos, a seleção visa à redução desse Seleção número por meio da escolha do candidato que melhor atende aos critérios da vaga oferecida (MILKOVICH; BOUDREAU, Seleção de pessoal comprometido com a causa ambiental e sensível a ela, com grande potencial de contribuição para a gestão ambiental da empresa.
Selecionar pessoas comprometidas com o meio ambiente facilita a sensibilização desses novos funcionários às questões de gestão ambiental. 2000). 
- RAM - REVISTA DE ADMINISTRAÇÃO MACKENZIE, V. 10, N. 4 •

\section{QUADRO 3 (CONTINUAÇÃO)}

DEFINIÇÕES DOS FATORES DE RECURSOS HUMANOS:

ABORDAGEM CLÁSSICA, NO CONTEXTO DA GESTÃO AMBIENTAL E IMPORTÂNCIA ORGANIZACIONAL

\begin{tabular}{|c|c|c|c|}
\hline $\begin{array}{l}\text { ATOR DE } \\
\text { RECURSOS } \\
\text { HUMANOS }\end{array}$ & DEFINIÇÃO TRADICIONAL & $\begin{array}{l}\text { DEFINIÇÃO NO CONCEITO } \\
\text { DA GESTÃO AMBIENTAL } \\
\text { EMPRESARIAL }\end{array}$ & $\begin{array}{l}\text { IMPORTÂNCIA PARA } \\
\text { A GESTÃO AMBIENTAL } \\
\text { EMPRESARIAL }\end{array}$ \\
\hline Treinamento & $\begin{array}{l}\text { O treinamento pode ser } \\
\text { compreendido como } \\
\text { o processo sistemático } \\
\text { por meio do qual } \\
\text { o comportamento } \\
\text { dos trabalhadores é } \\
\text { orientado para levar } \\
\text { a cabo o conjunto de } \\
\text { objetivos organizacionais } \\
\text { (IVANCEVICH, 1995). }\end{array}$ & $\begin{array}{l}\text { Treinamento } \\
\text { ambiental de todos } \\
\text { os funcionários da } \\
\text { organização e dos } \\
\text { terceirizados, com } \\
\text { ênfase nos aspectos } \\
\text { ambientais inerentes a } \\
\text { cada cargo. }\end{array}$ & $\begin{array}{l}\text { Proporciona o } \\
\text { desenvolvimento de } \\
\text { conhecimentos sobre } \\
\text { a política ambiental da } \\
\text { empresa, suas práticas } \\
\text { e atitudes necessárias. }\end{array}$ \\
\hline $\begin{array}{l}\text { Avaliação de } \\
\text { desempenho }\end{array}$ & $\begin{array}{l}\text { A avaliação de } \\
\text { desempenho é } \\
\text { utilizada para analisar } \\
\text { a performance do } \\
\text { funcionário ante } \\
\text { suas incumbências } \\
\text { (IVANCEVICH, 1995). }\end{array}$ & $\begin{array}{l}\text { Avaliação e registro } \\
\text { do desempenho } \\
\text { ambiental do } \\
\text { funcionário ao longo } \\
\text { de sua trajetória na } \\
\text { empresa. }\end{array}$ & $\begin{array}{l}\text { Fornece um feedback } \\
\text { sobre o desempenho } \\
\text { ambiental do } \\
\text { funcionário, para } \\
\text { fins de inibição de } \\
\text { comportamentos não } \\
\text { desejados ou reforço } \\
\text { de comportamentos } \\
\text { louváveis. }\end{array}$ \\
\hline Recompensas & $\begin{array}{l}\text { A política de recompensas } \\
\text { tem por finalidade atrair, } \\
\text { reter e motivar os melhores } \\
\text { funcionários, encorajando } \\
\text { o desenvolvimento de } \\
\text { conhecimentos, atitudes e } \\
\text { habilidades que fomentem } \\
\text { a consecução dos objetivos } \\
\text { empresariais (GÓMEZ; } \\
\text { LORENTE; CABRERA, } \\
\text { 2005). }\end{array}$ & $\begin{array}{l}\text { Implementação } \\
\text { de um sistema } \\
\text { de recompensas } \\
\text { financeiras e não } \\
\text { financeiras para } \\
\text { funcionários com } \\
\text { destacado potencial } \\
\text { de contribuição para a } \\
\text { gestão ambiental. }\end{array}$ & $\begin{array}{l}\text { A recompensa } \\
\text { financeira ou não } \\
\text { financeira motiva } \\
\text { os funcionários } \\
\text { a ponderar } \\
\text { constantemente as } \\
\text { questões ambientais } \\
\text { em suas atividades. }\end{array}$ \\
\hline
\end{tabular}




\section{QUADRO 3 (CONCLUSÃO)}

\begin{tabular}{|c|c|c|c|}
\hline $\begin{array}{l}\text { ATOR DE } \\
\text { RECURSOS } \\
\text { HUMANOS }\end{array}$ & DEFINIÇÃO TRADICIONAL & $\begin{array}{l}\text { DEFINIÇÃO NO CONCEITO } \\
\text { DA GESTÃO AMBIENTAL } \\
\text { EMPRESARIAL }\end{array}$ & $\begin{array}{l}\text { IMPORTÂNCIA PARA } \\
\text { A GESTÃO AMBIENTAL } \\
\text { EMPRESARIAL }\end{array}$ \\
\hline $\begin{array}{l}\text { Articulação de } \\
\text { equipes }\end{array}$ & $\begin{array}{l}\text { Equipe remete a } \\
\text { um pequeno grupo } \\
\text { de pessoas, com } \\
\text { conhecimentos } \\
\text { complementares, que } \\
\text { objetivam alcançar metas } \\
\text { e objetivos compartilhados } \\
\text { (KATZENBACH; SMITH, } \\
\text { 1993). }\end{array}$ & $\begin{array}{l}\text { Composição de } \\
\text { equipes, funcionais e } \\
\text { interfuncionais, para a } \\
\text { abordagem e solução } \\
\text { de problemas e } \\
\text { melhorias ambientais. }\end{array}$ & $\begin{array}{l}\text { Permite a difusão } \\
\text { de conhecimento } \\
\text { e a combinação } \\
\text { de competências } \\
\text { ambientais de diversos } \\
\text { funcionários para a } \\
\text { solução de problemas } \\
\text { ambientais complexos. }\end{array}$ \\
\hline
\end{tabular}

\section{Cultura organizacional}

diz respeito ao conjunto de pressupostos básicos que determinado grupo Gestão inventou, descobriu ou da cultura desenvolveu em seu organizacional processo de aprendizagem, a fim de lidar com

A questão ambiental passa a ser gerenciada como um novo valor da organização.
A questão ambiental torna-se um valor compartilhado pelos funcionários, ao lado dos outros valores que compõem a cultura da empresa.

problemas de adaptação

externa e integração interna (SCHEIN, 1990).

\begin{tabular}{|c|c|c|c|}
\hline $\begin{array}{l}\text { Práticas de } \\
\text { aprendizagem } \\
\text { organizacional }\end{array}$ & $\begin{array}{l}\text { Aprendizagem } \\
\text { organizacional pode ser } \\
\text { compreendida como um } \\
\text { processo em que ocorrem } \\
\text { aquisição, interpretação } \\
\text { e distribuição de } \\
\text { informações que formam } \\
\text { a memória organizacional } \\
\text { (CASEY, 2005). }\end{array}$ & $\begin{array}{l}\text { Incentivo à aquisição, } \\
\text { à reflexão e ao } \\
\text { compartilhamento } \\
\text { de informações e } \\
\text { ideias sobre gestão } \\
\text { ambiental. }\end{array}$ & $\begin{array}{l}\text { Fomenta o } \\
\text { compartilhamento } \\
\text { de informações sobre } \\
\text { gestão ambiental, } \\
\text { por meio constante e } \\
\text { troca de experiências } \\
\text { e reflexões entre os } \\
\text { funcionários. }\end{array}$ \\
\hline
\end{tabular}

Fonte: Elaborado pelos autores. 


\section{MATERIAIS E MÉTODOS}

A pesquisa de campo desenvolveu-se sob os postulados do método qualitativo, próprio para o estudo de fenômenos complexos e ainda pouco explorados pela academia, relevante, pois, para a investigação do relacionamento entre os fatores de recursos humanos e o desenvolvimento de produtos ambientais, temática considerada emergente. Para atingir o objetivo da pesquisa, adotou-se a estratégia de pesquisa de campo pautada na condução de dois estudos de casos. O estudo de caso, conforme afirma Yin (2005), é relevante para o estudo de fenômenos contemporâneos, com limites e fronteiras ainda não desvendados, vinculados às características idiossincráticas da dinâmica de uma dada organização. Em suma, o estudo de caso é pertinente como proposta metodológica, pois permite a investigação de um fenômeno com fronteiras pouco claras em seu contexto original e particular, tal como o realizado nesta pesquisa.

A amostra de pesquisa foi escolhida intencionalmente para poder se observar o fenômeno com profundidade, ao mesmo passo que se investigam empresas que gozam de reconhecimento público de suas práticas de gestão ambiental. A amostra foi, assim, composta por duas empresas industriais localizadas no Brasil, cujas características são apresentadas no Quadro 4. A escolha por empresas industriais justifica-se à medida que tais organizações caracterizam-se por processos de transformação de matérias-primas e recursos naturais em produtos acabados, gerando, portanto, impactos ambientais superiores às suas congêneres prestadoras de serviço.

A dinâmica da pesquisa de campo desenrolou-se durante três fases. A primeira delas constitui-se na fundamentação dos principais conceitos teóricos sobre o tema apresentado no estado da arte da literatura, para posterior elaboração de um roteiro de pesquisa alinhado ao objetivo do trabalho. Esse roteiro, tripartite, versou sobre temas de gestão de recursos humanos, gestão ambiental e difusão de práticas ambientais na área de produção, no contexto do desenvolvimento de produtos. A elaboração dos roteiros de entrevistas baseou-se, adicionalmente, na pesquisa sobre desenvolvimento de produtos ambientais publicada por Handfield et al. (200I).

A segunda fase da pesquisa constituiu-se de contato junto às empresas para a viabilização da pesquisa. Após aprovada a realização da pesquisa, foram entrevistados diversos membros organizacionais, dos vários níveis hierárquicos, principalmente das áreas de gestão de pessoas, gestão ambiental e administração da produção. A escolha dessas áreas se pautou nos métodos de pesquisas similares, como a realizada por Boiral (2002). 
QUADRO 4

CARACTERIZAÇÃO DAS EMPRESAS A E B

E DO PROCESSO DE COLETA DE DADOS




A terceira fase compreendeu a análise e sistematização das informações expostas pelos respondentes, complementando-se tais informações com os documentos coletados e algumas observações realizadas nessas organizações, para posterior relacionamento com a teoria previamente revisada. Tal sistematização foi organizada para produzir contraposições entre a teoria e prática, com o objetivo de explorar os seguintes eixos temáticos: estágios evolutivos da gestão ambiental em que essas empresas se encontram, desenvolvimento de produtos ambientais no contexto da manufatura ambientalmente responsável e relacionamento entre fatores de recursos humanos e desenvolvimento de produtos ambientais.

\section{RESULTADOS}

\subsection{A INSERÇÃO DA DIMENSÃO AMBIENTAL NO PROCESSO DE DESENVOLVIMENTO DE PRODUTOS}

A empresa A apresenta um padrão histórico de preocupações com o meio ambiente que se iniciou com declarações de seu fundador sobre a necessidade da empresa de manter-se ambientalmente adequada. Tal preocupação deve-se ao grande impacto ambiental gerado para a obtenção da matéria-prima primordial em seus produtos: a madeira, processo integrado verticalmente aos demais empreendimentos organizacionais. Tal fato levou a empresa a projetar e gerenciar uma reserva de árvores que logrou, em I999, a certificação de manejo sustentável. A certificação de suas instalações com a norma ISO I400I ocorreu apenas em 2002, por força de incentivos da matriz europeia e para atender aos requisitos do mercado consumidor, em grande medida, do mercado externo, com destaque para a União Europeia, onde a legislação ambiental revela-se mais severa.

A empresa B iniciou seu processo de adequação ambiental em meados da década de I970, por influência de um de seus diretores corporativos. Sua certificação ISO I400I ocorreu no ano de 2003. Destaca-se que a empresa possui uma sistemática de prevenção da poluição consolidada corporativamente, em que iniciativas de melhoria do desempenho ambiental devem coincidir com a exploração de oportunidades para a redução dos custos operacionais.

Em termos de estágios evolutivos, pode-se considerar que a gestão ambiental da empresa A encontra-se no estágio intermediário, isto é, busca-se a prevenção da poluição, mas a questão ambiental ainda não influi no conteúdo da estratégia da organização de forma crítica. Por exemplo, a despeito de os entrevistados afirmarem ser imprescindível a extensão das atividades de gestão ambiental aos fornecedores, ainda não há práticas consolidadas nesse sentido. 
Não obstante, os projetos de gestão ambiental analisados evidenciam um enfoque de gestão ambiental pautado na redução de insumos básicos, tais como energia elétrica e água no ciclo produtivo. O principal condicionante de suas iniciativas é o atendimento às demandas de desempenho de seus mercados consumidores, observando-se, pois, uma predominância de fontes externas de pressão para a gestão ambiental.

A empresa B pode ser classificada no estágio de gestão ambiental estratégica, pois, ao longo de mais de três décadas, a dimensão ambiental atingiu um nível diferenciado de maturidade: é patente a preocupação da organização com o seu desempenho ambiental, alinhando as atividades de gestão ambiental aos objetivos empresariais. Nesse sentido, verificam-se a exploração de novos nichos em mercados ambientalmente conscientes, a elaboração de estratégias de marketing ambiental, parcerias com fornecedores para redução dos impactos ambientais em subcomponentes de produtos e bancos de dados para o gerenciamento da informação ambiental e para sua disseminação. Essa empresa, atuante em alguns nichos do setor químico, tende a acompanhar a crescente consciência ambiental desse setor industrial.

Em ambas as empresas, a inserção da dimensão ambiental no processo de desenvolvimento de produtos vem ocorrendo de forma gradual, mas nuanças podem ser observadas em decorrência do próprio estágio de maturidade em que a gestão ambiental dessas duas organizações se encontra.

$\mathrm{Na}$ empresa $\mathrm{A}$, não se pode afirmar que haja uma forte contribuição de sua alta administração para desenvolver produtos com elevado desempenho ambiental, apesar de ser observado estímulo para o fortalecimento da gestão ambiental como um todo. Entretanto, não há mecanismos formais que possam estender esses estímulos aos fornecedores. A coordenação da inserção da dimensão ambiental no desenvolvimento de produtos não é evidente. O gerente de pesquisa e desenvolvimento (P\&D) influi nesse processo como consultor, a fim de orientar os desenvolvedores sobre produtos e substâncias que não podem ser utilizados em um dado projeto. A empresa não possui um benchmarking sobre tal temática, e as informações requeridas não são gerenciadas no contexto dos princípios clássicos de desenvolvimento de produtos ambientais, tais como o Design for Environment (DfE) e a Análise do Ciclo de Vida dos produtos (ACV). As informações ambientais consideradas nos processos de desenvolvimento dizem respeito à adequação à legislação ambiental da União Europeia e dos Estados Unidos, seguindo paralelamente os patamares permitidos de toxicologia. Observa-se que a dimensão ambiental é tratada como limitante das possibilidades de desenvolvimento, sendo os critérios ambientais legais respeitados no início do processo, sem que haja uma gestão do conhecimento ambiental e aprendizagem proporcionada por projetos anteriores. 
Na empresa B, observa-se grande esforço, suportado pelos programas corporativos de gestão ambiental, para inserir a dimensão ambiental no desenvolvimento de todos os produtos, para além de uma perspectiva legalista da inserção da dimensão ambiental nesse processo. Para tanto, a empresa vem adotando princípios de desenvolvimento de produtos ambientais, com destaque para DfE e ACV. Cabe registrar que uma das metas dessa empresa é, até 20ıo, analisar o ciclo de vida de seus mais de 3.200 produtos. Esse projeto é apoiado pela alta administração, suportado pelos dirigentes corporativos e difundido como importante meta para os funcionários da empresa.

A coordenação do processo de desenvolvimento de produtos ambientais foi incrementada na empresa B, a partir de 2003 , pela contratação de um funcionário com elevado nível instrucional para o cumprimento da referida meta. Banco de dados com informações ambientais úteis ao desenvolvimento de produtos pode ser acessado via intranet. Sob o signo da dupla busca de reduzir custos operacionais e gerar inovações à luz do paradigma ambiental, a empresa criou novos produtos e vem reduzindo a taxa de emissão de seus gases de efeito estufa emitidos durante o processo produtivo.

\subsection{FATORES DE RECURSOS HUMANOS E DESENVOLVIMENTO DE PRODUTOS AMBIENTAIS}

A interação entre os fatores de recursos humanos e o desenvolvimento de produtos ambientais nas empresas analisadas apresenta similaridades e descontinuidades. Tanto na empresa A quanto na B, pode-se observar grande potencial para melhoria desse relacionamento, se houver maior aproximação entre as áreas de gestão ambiental e gestão de pessoas das empresas. Além disso, em ambas as empresas, o treinamento ambiental despontou como o principal fator de recursos humanos que suporta a gestão ambiental empresarial. As contribuições e eventuais motivações para o desenvolvimento de inovações ambientais em produtos e processos tendem a ser desconsideradas por ambas as empresas no momento de preenchimento de um posto de trabalho em vacância, no âmbito de uma perspectiva holística de análise e descrição de cargos. De forma isolada, mas de grande importância, observa-se na empresa B o recrutamento e a seleção de um funcionário com título de doutorado obtido no exterior para preencher o cargo de analista de Ciclo de Vida de Produtos.

Findas as similaridades, o que se evidencia é uma descontinuidade entre a integração dos demais fatores de recursos humanos e a inserção da dimensão ambiental no desenvolvimento de produtos. A principal diferença pode ser observada no processo de avaliação do desempenho ambiental do funcionário durante o processo de desenvolvimento de produtos e em suas demais ativida- 
des organizacionais. Isso porque, enquanto na empresa A não estão presentes instrumentos formais para a avaliação desse desempenho, na empresa B cada gerência, inclusive a área de $P \& D$, possui metas anuais de melhorias que devem ser efetuadas para a consolidação da gestão ambiental empresarial. A recompensa para o desempenho satisfatório é, assim, possível somente na empresa B, onde os funcionários envolvidos em um dado projeto para melhoria do desempenho ambiental que obtiver concomitantemente melhoria na redução de custos operacionais podem ser agraciados com diversas formas de reconhecimento público perante os pares, viagens à matriz nos Estados Unidos e novas oportunidades de ascensão profissional.

Tais diferenças na configuração entre fatores tradicionais de recursos humanos podem ser notadas - e até mesmo explicadas - por diferenças observadas nos fatores competitivos de recursos humanos: gestão da cultura organizacional, articulação do trabalho em equipes e aprendizagem organizacional. A despeito de ambas as empresas declararem as questões ambientais como seu objetivo, esse pressuposto encontra eco mais robusto na empresa $\mathrm{B}$. $\mathrm{Na}$ empresa A, em termos de desenvolvimento de produtos, pode-se observar que a dimensão ambiental tende a ser gerenciada de maneira pontual, à luz das possibilidades identificadas na legislação dos mercados consumidores. Dessa forma, gerenciada como um requisito a ser cumprido sem maiores reflexões e desintegrada dos objetivos e das metas da empresa, a dimensão ambiental tende a encontrar dificuldades para o gerenciamento como valor organizacional.

Já na empresa B, observa-se que a dimensão ambiental proporciona, há mais de três décadas, oportunidade para se repensarem os processos e produtos organizacionais à luz de novos pressupostos. Tal dimensão é conhecida pelos funcionários por seu efeito no alcance das metas empresariais - tanto para aquelas que focam a redução de custos operacionais quanto para as que focam a geração de inovações -, o que pode ser verificado tanto pela existência de metas de curto prazo que recaem sobre todos os funcionários, quanto para metas de longo prazo, como incorporar a dimensão ambiental no desenvolvimento de produtos, processos, gestão da qualidade, logística etc. Observam-se, nessa organização, inúmeras inovações, incrementais e radicais, obtidas por meio da gestão da dimensão ambiental como valor organizacional.

As diferenças no desenvolvimento de produtos ambientalmente adequados podem ser adicionalmente analisadas à luz das práticas de aprendizagem organizacional das empresas A e B. Na empresa A, as informações ambientais do desenvolvimento de produtos estão pautadas na legislação internacional do mercado consumidor predominante. A aprendizagem ambiental não compreende, assim, reflexão constante, com absorção de experiências e exploração de novos paradigmas ambientais. $\mathrm{Na}$ empresa $\mathrm{B}$, a aprendizagem ambiental foi favore- 
cida pela adoção dos princípios DfE e ACV, e apoiada por investimentos em gestão ambiental que envolvem a aquisição de softwares e hardwares para monitoramento da emissão de gases do efeito estufa durante o processo produtivo. Esses sistemas fornecem informações para a condução de melhorias ambientais em produtos.

Na empresa A, a articulação de equipes para o desenvolvimento de produtos é inibido, conforme relatos dos funcionários. Espera-se, nessa empresa, que os funcionários desenvolvam seus projetos predominantemente de forma individual, podendo-se consultar os pares e o supervisor sempre que necessário. $\mathrm{Na}$ empresa B, a organização de equipes é apresentada como a forma típica que conduz os projetos de melhoria ambiental. Os projetos de redução da poluição dessa organização revelam elevado grau de complexidade, exigindo a combinação de habilidades, conhecimentos e atitudes. À luz do desenvolvimento de produtos, o trabalho em equipe é observado pela integração dos responsáveis pela ACV do produto na equipe típica de desenvolvimento.

Para fins de exemplificação, é possível analisar dois casos de melhorias ambientais em produtos das duas empresas. Na empresa A, vem ocorrendo a substituição de um dos seus componentes de embalagem, até então de PVC, por plástico reciclado. Essa decisão é oriunda de pressões da legislação europeia. A decisão foi tomada após negociações entre o diretor de P\&D e a alta administração da empresa. Houve, assim, pouca interação entre os fatores de recursos humanos nessa melhoria, uma vez que as atividades tradicionais e competitivas de recursos humanos não se mostram fortemente vinculadas a tal melhoria.

Na empresa B, um caso observado foi a busca por melhoria em um dos produtos mais representativos em termos de retorno financeiro para ela. Esse produto é obtido por meio da fusão de suas partes esponjosas, o que culmina na liberação de compostos orgânicos voláteis, com efeitos negativos sobre a atmosfera. O ciclo de vida do produto foi analisado e repensado à luz dos princípios de DfE. Dessa forma, alterou-se o desenvolvimento a fim de: a) adotar processos sem solventes tradicionais (optou-se por aqueles à base de água); b) recuperar os resíduos desse solvente à base de água; e c) oxidar o solvente para reúso.

Esse projeto da empresa B, cujo investimento inicial superou os três milhões de dólares, apresentou retorno desse dispêndio em um ano, possibilitando adicionalmente a redução no consumo de insumos até então mais caros e concomitante possibilidade de reutilização dos solventes à base de água, por meio da implantação de uma estação de tratamento e reúso do produto. Esse projeto utilizou conhecimentos ambientais prévios acumulados ao longo dos anos, equipe de especialistas, incentivos da alta administração e pessoal especializado. Os desenvolvedores foram recompensados com diversas formas de reconhecimen- 
to público, podendo realizar viagens para proferir palestras sobre o assunto. $\mathrm{O}$ resultado foi a redução de Io०\% nas taxas de emissões de compostos orgânicos voláteis para a atmosfera.

\section{CONSIDERAÇÕES FINAIS}

O campo de pesquisa sobre a interação entre gestão ambiental e fatores de recursos humanos é recente, principalmente quando o enfoque é direcionado para a análise do processo de desenvolvimento de produtos. É nesse contexto que a presente pesquisa objetiva trazer contribuições. Para tanto, utilizou-se um referencial teórico sobre os temas, identificando-se questões relevantes para a análise empírica. Conduziu-se um estudo de dois casos nas empresas A e B.

Os resultados evidenciam que essas empresas se encontram em diferenciados estágios de maturidade em gestão ambiental. Enquanto a empresa A tem atividades de gestão ambiental pautadas, predominantemente, em cumprimento à legislação ambiental e atendimento aos requisitos dos consumidores, na empresa B observa-se uma gestão ambiental orientada para o incremento em competitividade e exploração de novos produtos, concomitantes à redução de custos operacionais.

A diferença entre os estágios evolutivos da gestão ambiental mostra-se determinante do grau de inserção da variável ambiental no processo de desenvolvimento de produtos, possuindo implicações para o relacionamento com os fatores de recursos humanos (Quadro 5). O estágio intermediário em gestão ambiental na empresa A é conducente a um processo de desenvolvimento de produtos que considera aspectos ambientais de forma pontual - pautada no cumprimento da legislação atual ou de sua tendência -, o que proporciona fracas interações com a totalidade de fatores de recursos humanos. Na empresa B, a excelência em gestão ambiental passou a influenciar o processo de desenvolvimento de todos os produtos por meio da inserção de princípios de DfE e ACV. Na empresa B, essa nova concepção requer interfaces e é favorecida por aquelas que a organização mantém com fatores de recursos humanos. Foram decisivas alterações nos processos de descrição de cargo, recrutamento e seleção do ACV de produtos. A gestão da dimensão ambiental como um valor da empresa favoreceu a inserção de um "repensar" o desenvolvimento de produtos, que, por meio do trabalho em equipe, da gestão das informações e da aprendizagem histórica, tende a gerar inovações ambientais de alto valor agregado, as quais possibilitam aos seus desenvolvedores uma avaliação de desempenho que culmine em diversas formas de reconhecimento público, internas e externas à empresa. 


\section{QUADRO 5}

SISTEMATIZAÇÃO DOS RESULTADOS DO ESTUDO DE CASOS

\begin{tabular}{|c|c|c|c|}
\hline & GESTÃO AMBIENTAL & $\begin{array}{l}\text { INSERÇÃO DA DIMENSÃO } \\
\text { AMBIENTAL NO } \\
\text { DESENVOLVIMENTO DE } \\
\text { PRODUTOS }\end{array}$ & $\begin{array}{l}\text { RELACIONAMENTOS ENTRE O } \\
\text { DESENVOLVIMENTO DE PRODUTOS } \\
\text { AMBIENTAIS E FATORES } \\
\text { HUMANOS }\end{array}$ \\
\hline $\begin{array}{c}\text { EMPRESA } \\
\mathrm{A}\end{array}$ & $\begin{array}{l}\text { ISO 14001, ênfase } \\
\text { no cumprimento da } \\
\text { legislação ambiental } \\
\text { atual e de suas } \\
\text { tendências. Está no } \\
\text { estágio intermediário } \\
\text { de evolução de gestão } \\
\text { ambiental: integração } \\
\text { interna. }\end{array}$ & $\begin{array}{l}\text { Inserção via } \\
\text { cumprimento } \\
\text { da legislação } \\
\text { - principalmente } \\
\text { europeia. Pontualidade } \\
\text { da integração e } \\
\text { ausência de princípios } \\
\text { norteadores. }\end{array}$ & $\begin{array}{l}\text { Fraco relacionamento. } \\
\text { Como consequência, não é } \\
\text { observada interação entre o } \\
\text { desenvolvimento de produtos } \\
\text { ambientais e fatores de } \\
\text { recursos humanos. }\end{array}$ \\
\hline $\begin{array}{c}\text { EMPRESA } \\
\text { B }\end{array}$ & $\begin{array}{l}\text { ISO 14001, ênfase na } \\
\text { integração da dimensão } \\
\text { ambiental ao processo } \\
\text { de inovação. Estágio de } \\
\text { integração externa. }\end{array}$ & $\begin{array}{l}\text { Inserção em todos } \\
\text { os processos de } \\
\text { desenvolvimento } \\
\text { de produtos. } \\
\text { Equipe liderada } \\
\text { por especialista e } \\
\text { adoção de princípios } \\
\text { norteadores (DfE e } \\
\text { ACV). }\end{array}$ & $\begin{array}{l}\text { Relacionamento mais } \\
\text { presente do que na empresa } \\
\text { A. Foco no trabalho em } \\
\text { equipe e na gestão da } \\
\text { dimensão ambiental como } \\
\text { valor organizacional, } \\
\text { dinamizando o sistema de } \\
\text { aprendizagem. Destaque } \\
\text { para os fatores de recursos } \\
\text { humanos de avaliação de } \\
\text { desempenho e recompensas } \\
\text { não financeiras. }\end{array}$ \\
\hline
\end{tabular}

Fonte: Elaborado pelos autores.

Tais considerações devem ser ponderadas no contexto próprio e idiossincrático que se configura em estudo de casos. Sugere-se, a fim de complementar tais observações e métodos, a condução de pesquisa quantitativa, com a recomendação de que sejam exploradas as seguintes hipóteses:

- Hı: a inserção da dimensão ambiental no processo de desenvolvimento de produtos está fortemente correlacionada com o estágio evolutivo de gestão ambiental empresarial.

- H2: o grau de contribuições dos fatores humanos para a gestão ambiental está fortemente correlacionado ao estágio evolutivo dessa área. 
- $\mathrm{H}_{3}$ : o relacionamento entre gestão ambiental e fatores de recursos humanos tende a possuir correlação mais forte quanto mais robusta for a conscientização ambiental de um setor industrial ao qual as empresas sob análise pertencerem.

\section{REFERÊTCIAS}

ABOULNAGA, I. A. Integrating quality and environmental management as competitive business strategy for 2Ist century. Environmental Management and Health, v. 9, n. 2, p. 65-7I, I998.

ANGELL, L. C.; KLASSEN, R. D. Integrating environmental issues into the mainstream: an agenda for research in operations management. Journal of Operations Management, v. I7, p. 575-598, I999.

AZZONE, G.; BERTELÈ, U.; NOCI, G. At last we are creating environmental strategies which work. Long Range Planning, v. 30, n. 4, p. 562-571, I997.

BARBIERI, J. C. Gestão ambiental empresarial. São Paulo: Saraiva, 2004.

BOIRAL, O. Tacit knowledge and environmental management. Long Range Planning, v. 35, n. 3, p. 29I-3I7, 2002.

Global warming: should companies adopt a proactive strategy? Long Range Planning, v. 39, p. 3I5-330, 2006.

BOONS, F. Greening products: a framework for product chain management. Journal of Cleaner Production, v. IO, p. 495-505, 2002.

BRÍO, J. A.; FENÁNDEZ, E.; JUNQUERA, B. Management and employee involvement in achieving and environmental action-based competitive advantage: an empirical study. The International Journal of Human Resource Management, v. I8, n. 4, p. 49I-522, 2007.

BYGGETH, S.; BROMAN, G.; ROBÈRT, K. A method for sustainable product development based on a modular system of guiding questions. Journal of Cleaner Production, v. I5, p. I-II, 2007.

CASEY, A. Enhancing individual and organizational learning. Management Learning, v. 36, n. 2, p. I3I-I47, 2005.

CORAZZA, R. I. Gestão ambiental e mudanças da estrutura organizacional. Revista de Administração de Empresas (RAE-eletrônica), v. 2, n. 2, p. I-23, 2003.

DAILY, B. F.; HUANG, S. Achieving sustainability through attention to human resource factors in environmental management. International Journal of Operations \& Production Management, v. 2I, n. I2, p. I539-I552, 2001.

DONAIRE, D. Considerações sobre a influência da variável ambiental na empresa. Revista de Administração de Empresas (RAE), v. 34, n. 2, p. 68-77, I994.

Gestão ambiental na empresa. São Paulo: Atlas, I999.

FINKBEINER, M. et al. Application of Life Cycle Assessment for environmental certificate of the Mercedes-Benz S-Class. International Journal of Life Cycle Assessment, v. II, n. 4, p. 240-246, 2006.

GINSBERG, J. M.; BLOOM, P. N. Choosing the right green marketing strategy. MIT Sloan Management Review, v. 48, n. I, p. 79-85, 2004. 
GÓMEZ, P. J.; LORENTE, J. C.; CABRERA, R. V. Organizational learning and compensations strategies: evidence from the Spanish chemical industry. Human Resource Management, v. 44, n. 3 , p. 279-299, 2005 .

GOVINDARAJULU, N.; DAILY, B. F. Motivating employees for environmental improvement. Industrial Management \& Data Systems, v. I04, n. 4, p. 364-372, 2004.

HANDFIELD, R. et al. Integration environmental concerns into the design process: the gap between theory and practice. IEEE Transactions on Engineering Management, v. 48, n. 2, p. I89-208, 200 I.

HART, S. L. A natural-resource-based view of the firm. Academy of Management, v. 20, n. 4, p. 986-IOI4, I995.

HIRSCHL, B.; KONRAD, W.; SCHOLL, G. New concepts in product use for sustainable consumption. Journal of Cleaner Production, v. II, p. 873-88I, 2003.

HOFFMAN, A. J. Climate change strategy: the business logic behind voluntary greenhouse gas reduction. California Management Review, v. 47, n. 3, p. 2I-46, 2005.

HUNT, C. B.; AUSTER, E. R. Proactive environmental management: avoiding the toxic trap. MIT Sloan Management Review, v. 3I, n. 2, p. 7-I8, I990.

IVANCEVICH, J. M. Human resource management. Chicago: Irwin, I995.

JABBOUR, C. J. C.; SANTOS, F. C. A. The evolution of environmental management within organizations: toward a common taxonomy. Environmental Quality Management Journal (EQMJ), v. I6, p. 43-59, 2006.

Relationships between human resource dimensions and environmental management in companies: proposal of a model. Journal of Cleaner Production, v. I6, n. I, p. 5I-58, 2008.

JOHANSSON, G. Incorporating environmental concern in product development. Management of Environmental Quality: an International Journal, v. I7, n. 4, p. 42I-436, 2006.

KAEBERNICK, H.; KARA, S.; SUN, M. Sustainable product development and manufacturing by considering environmental requirements. Robotics and Computer Integrated Manufacturing, v. I9, p. 46I-468, 2003.

KATZENBACH, J. R.; SMITH, D. K. The wisdom of teams. Massachusetts: Harvard Business School Press, I993.

KUEHR, R. Environmental technologies: from a misleading interpretations to an operational categorization and definition. Journal of Cleaner Production, v. I5, n. I3-I4, p. I3I6-I320, 2007.

LUTTROPP, C.; LAGERSTEDT, J. EcoDesign and the ten golden rules: generic advice for merging environmental aspects into product development. Journal of Cleaner Production, v. I4, p. I396-I408, 2006.

MAIMON, D. Passaporte verde: gestão ambiental e competitividade. Rio de Janeiro: Qualitymark, I996.

MATHIEUX, F. et al. Ecodesign in the European Electronics industry. The Journal of Sustainable Product Design, v. I, p. 233-245, 200I.

MCCLOSKEY, J; MADDOCK, S. Environmental management: its role in corporate strategy. Management Decision, v. 32, n. I, p. 27-32, I994.

MILES, M. P.; COVIN, J. G. Environmental marketing: a source of reputational, competitive and financial advantage. Journal of Business Ethics, v. 23, n. 3, p. 299-3II, 2000.

MILKOVICH, G. T.; BOUdREAU, J. W. Administração de recursos humanos. São Paulo: Atlas, 2000. 
NAHUZ, M. A. R. O sistema ISO I4000 e a certificação ambiental. Revista de Administração de Empresas, São Paulo, v. 35, n. 6, p. 55-66, I995.

NISSINEN, A. et al. Developing benchmarks for consumer-oriented life cycle assessment-based environmental information on products, services and consumption patterns. Journal of Cleaner Production, v. I5, p. 538-539, 2007.

POLIZELLI, D.; PETRONI, L.; KRUGLIANSKAS, I. Gestão ambiental nas empresas líderes do setor de telecomunicações no Brasil. Rausp, v. 40, n. 4, p. 309-320, 2005.

POLONSKY, M. T.; OTTMAN, J. A. Exploratory examination of whether marketers include stakeholders in the green new product development process. Journal of Cleaner Production, v. 6, p. 269275, 1998.

PORTER, M. E.; LINDE, C. V. D. Green and competitive: ending the stalemate. Harvard Business Review, v. 73, n. 5, p. I20-I34, I995.

PRESTON, L. Sustainability at Hewlett-Packard: from theory to practice. California Management Review, v. 43, n. 3, p. 26-37, 2001.

PUJARI, D. Eco-innovation and new product development: understanding the influences on market performance. Technovation, v. 26, p. 76-85, 2006.

PUJARI, D.; WRIGHT, G.; PEATTIE, K. Green and competitive: influences on evironmental new product development performance. Journal of Business Research, v. 56, p. 657-67I, 2003.

RICHARDS, D. J.; FROSCH, R. A. The industrial green game: overview as perspectives. In: RICHARDS, D. J. (Org.). The industrial green game: implications for environmental design and management. Washington: National Academy Press, I997.

ROHRICH, S. S.; CUNHA, J. C. A proposição de uma taxonomia para a análise da gestão ambiental no Brasil. Revista de Administração Contemporânea, v. 8, n. 4, p. 8I-97, 2004.

ROSEN, C. M. Environmental strategy and competitive advantage: an introduction. California Management Review, v. 43, n. 3, p. 9-16, 2001.

ROTHENBERG, S. Sustainability through servicizing. MIT Sloan Management Review, v. 48, n. 2, p. 83-9I, 2007.

SANCHES, C. S. Gestão ambiental proativa. Revista de Administração de Empresas, v. 40, n. I, p. $76-87,2000$.

SCHEIN, E. H. Organizational culture. American Psychologist, v. 45, n. 2, p. I09-II9, I990.

SEIFFERT, M. E. B. ISO 14001: sistemas de gestão ambiental. São Paulo: Atlas, 2005.

SHERWIN, C. Design and sustainability. The Journal of Sustainable Product Design, v. 4, p. 2I-3I, 2004 .

STEEN, B. et al. Development of interpretation keys for environmental product declarations, Journal of Cleaner Production, v. I6, n. 5, p. 598-604, 2008.

STONE, L. J. When case studies are not enough: the influence of corporate culture and employee attitudes on the success of cleaner production initiatives. Journal of Cleaner Production, v. 8, p. 353359, 2000.

TINGSTRÖM, J.; SWANSTRÖM, L.; KARLSSON, R. Sustainability management in product development - the ABB experience. Journal of Cleaner Production, v. I4, p. I377-I385, 2006.

TISCHINER, U.; NICKEL, R. Eco-design in the printing industry. The Journal of Sustainable Product Design, v. 3, p. I9-23, 2003. 
WAAGE, S. A. Re-considering product design: a practical road map for integration of sustainability issues. Journal of Cleaner Production, v. I5, p. 638-649, 2007.

WU, H. J.; DUNN, S. C. Environmental responsible logistics systems. International Journal of Physical Distribution \& Logistics Management, v. 25, n. 2, p. 20-38, 1995.

YIN, R. K. Estudo de caso: planejamento e métodos. Porto Alegre: Bookman, 2005. 